\title{
Evaluation of EGFR abnormalities in patients with pulmonary adenocarcinoma: the need to test neoplasms with more than one method
}

\author{
Ruta Gupta, Aditi M Dastane, Farahnaz Forozan, Amin Riley-Portuguez, Fai Chung, \\ Jean Lopategui and Alberto M Marchevsky \\ Departments of Pathology and Laboratory Medicine and Thoracic Surgery, Cedars Sinai Medical Center, \\ Los Angeles, CA, USA
}

\begin{abstract}
Patients with advanced pulmonary adenocarcinoma exhibiting overexpression or mutation of epidermal growth factor receptor tend to respond better to targeted therapy with tyrosine kinase inhibitors such as gefitinib and erlotinib. There is no consensus regarding how these neoplasms should be routinely tested for epidermal growth factor receptor (EGFR) and whether the results of immunohistochemistry (IHC), mutation analysis and fluorescent in situ hybridization correlate with each other or are independent predictive variables. We tested 100 pulmonary adenocarcinomas from patients with stage III or IV disease for EGFR abnormalities using IHC, PCR and fluorescent in situ hybridization (FISH) and compared the results using $\kappa$ and other statistical methods. The sensitivity of each test to detect an EGFR abnormality and its negative predictive value to estimate the presence of an abnormal test result by the other two methods were calculated. Abnormal EGFR test results were found in 62,40 and $24 \%$ by IHC, FISH and PCR, respectively. $\kappa$ statistics yielded poor concordance between the results of the EGFR tests ( $\kappa=0.3$, and 0.2 for IHC and PCR and for PCR and FISH, respectively). Strong membranous immunoreactivity in more than $90 \%$ of the tumor cells was found to correlate with amplification or polysomy. PCR when used as a single test is likely to underestimate the presence of EGFR abnormalities that may significantly predict response to tyrosine kinase inhibitors. The need to standardize the approach to EGFR testing in patients with advanced pulmonary adenocarcinoma is discussed.
\end{abstract}

Modern Pathology (2009) 22, 128-133; doi:10.1038/modpathol.2008.182; published online 7 November 2008

Keywords: adenocarcinoma; EGFR; overexpression; amplification; polysomy

Lung cancer is the most frequent cause of cancerrelated deaths with less than $15 \%$ 5-year survival. ${ }^{1}$ Targeted therapy with epidermal growth factor receptor (EGFR) inhibitors such as gefitinib (Iressa ${ }^{\circledR}$, Astra-Zeneca, UK) and erlotinib (Tarceva ${ }^{\mathbb{R}}$, OSI/ Genentech, USA), has been recently approved as second or third line therapy for patients with advanced pulmonary adenocarcinoma with response rates varying from 10 to $27 \% .^{2}$ EGFR is a member of the erbB family of tyrosine kinase receptor proteins which is important in survival and proliferation of tumor cells. Overexpression or mutation in the tyrosine kinase domain of these receptors leading to inappropriate activation of the ras-antiapoptotic cascade have been observed in

Correspondence: Dr AM Marchevsky, MD, Department of Pathology and Laboratory Medicine, Cedars-Sinai Medical Center, 8700 Beverly Boulevard, Los Angeles, CA 90048, USA.

E-mail: marchevsky@cshs.org

Received 11 July 2008; revised 3 October 2008; accepted 6 October 2008; published online 7 November 2008
$43-89 \%$ of the non-small cell carcinomas of the lung. Studies by Clark et al, Chou et al and others have shown that although both squamous-cell carcinomas and adenocarcinomas may demonstrate immunoreactivity for EGFR or harbor EGFR mutations, squamous-cell carcinomas are not responsive to tyrosine kinase inhibitors. ${ }^{3-6}$

Several studies have evaluated for the presence of EGFR overexpression using immunohistochemistry (IHC), polysomy and amplification using fluorescent in situ hybridization (FISH), and gene mutations using the PCR. A recent systematic review of the literature with meta-analysis confirmed that EGFR abnormalities in patients with pulmonary adenocarcinoma detectable by either IHC, FISH or PCR significantly correlate with response to gefitinib therapy. ${ }^{7}$ The review also identified considerable variability in the methodology used in different studies and in the predictive value of their results for response to getifinib and erlotinib therapy. ${ }^{5,7-9}$ For example, Parra et al have suggested that the detection of EGFR overexpression by IHC may not 
offer predictive information, although Hirsch et al have shown a significant correlation between EGFR overexpression by IHC and response to tyrosine kinase inhibitor therapy. ${ }^{9,10}$ Hirsch et al and other have proposed that detection of polysomy and gene amplification using FISH provides a valuable predictive test. ${ }^{9}$ Mitsudomi et al have proposed that mutations of EGFR correlate significantly with response to gefitinib therapy; in contrast, Cappuzo et al did not show similar results. ${ }^{8,11}$ The differences in results may reflect variations in patient demographics, therapeutic methods, variable end points to assess a significant response, variations in testing methodology and variability in interpretation of test results. ${ }^{7,12}$

Limited studies have analyzed the criteria needed to define positive immunoreactivity for EGFR. ${ }^{12}$ Only few studies have compared whether EGFR abnormalities detectable by IHC, FISH or PCR correlate with each other or represent independent variables. $^{9,12-15}$ We studied 100 consecutive pulmonary adenocarcinomas with the three methods to evaluate the sensitivity of each of these three methods to detect EGFR abnormalities and determine whether these changes correlate with each other or are independent variables.

\section{Materials and methods}

Selected paraffin blocks of formalin-fixed tissues from 100 consecutive pulmonary adenocarcinomas were retrieved from the archives of Department of Pathology and Laboratory Medicine, Cedars Sinai Medical Center after institutional review board approval. These included lung tissue from 64 women and 36 men with American Joint Committee stages III and IV disease. All the tumors were classified according to the World Health Organization classification system. ${ }^{16}$ They included 61 adenocarcinomas, 27 bronchioloalveolar carcinomas and 12 tumors with mixed bronchioalveolar carcinoma and adenocarcinoma histology. The best single-tissue block from each case containing representative tumor and excluding areas of extensive hemorrhage, necrosis and/or fibrosis was selected for EGFR testing, using IHC, FISH and PCR. Treatment and follow-up information were not recorded and will be the subject of a future study.

\section{Immunohistochemistry}

The sections from the 100 cases were deparaffinized and hydrated. The slides were loaded on the Dako Autostainer (Dako North America Inc., Carpinteria, CA, USA) using the EGFR PharmDx Kit (Dako North America Inc.) and protocol. Enzyme digestion was performed with Dako Proteinase K. The slides were counterstained with hematoxylin and immunostaining. The sections were then evaluated at low magnification $(\times 10)$ using the criteria suggested by
Hirsch et al. ${ }^{12}$ Distinct membranous staining of tumor cells was considered as a positive immunoreaction, whereas diffuse cytoplasmic or granular staining was considered as negative immunoreaction. The percent proportion of tumor cells that were immunoreactive $(0-100 \%)$ were multiplied by the intensity of staining (1: negative or trace, 2: weak, 3 : moderate and 4: intense) (Figure 1). The IHC scores were tabulated in increments of 50 as $0-49,50-99$, 100-149, 150-199, 200-249, 250-299, 300-349 and 350-400. In addition, scores of 300 and above were considered as positive, using the criteria proposed by Hirsh et al. ${ }^{12}$ The IHC scores were compared statistically with the presence of EGFR amplification or polysomy as detected by FISH and mutations as detected by PCR.

\section{PCR and Mutation Analysis}

All 100 cases were evaluated for deletions in exons 19 and 21 point mutation L858R. Patient samples were extracted using Qiagen QIAamp DNA mini extraction system standard protocol for formalinfixed paraffin-embedded tissue. Samples were quantitated using a NanoDrop-1000 spectrophotometer and diluted to $50 \mathrm{ng} / \mu \mathrm{l}$. PCR primers were designed for the regions flanking the mutations in exons 19 and 21 using the Primer3 alignment program. For size fragment detection, the forward primer for exon 19 was labeled with an infrared dye (WellRed ${ }^{\mathrm{TM}}$ ) and purified by high-performance liquid chromatography. Total of $25 \mathrm{ng}$ of DNA were amplified for each exon. After amplification, the samples were treated with 1:10 Exo-Sap (USB product no.: 78201). Amplified exon 19 samples were diluted 1:5 with double distilled water $\left(\mathrm{ddH}_{2} \mathrm{O}\right)$ and $40 \mu \mathrm{l}$ of capillary electrophoresis preparation solution (Beckman Coulter no. A20174) and $0.5 \mu \mathrm{l}$ of capillary electrophoresis size standard 600 (Beckman coulter no. 20088). Samples for the L858R were diluted 1:5 with

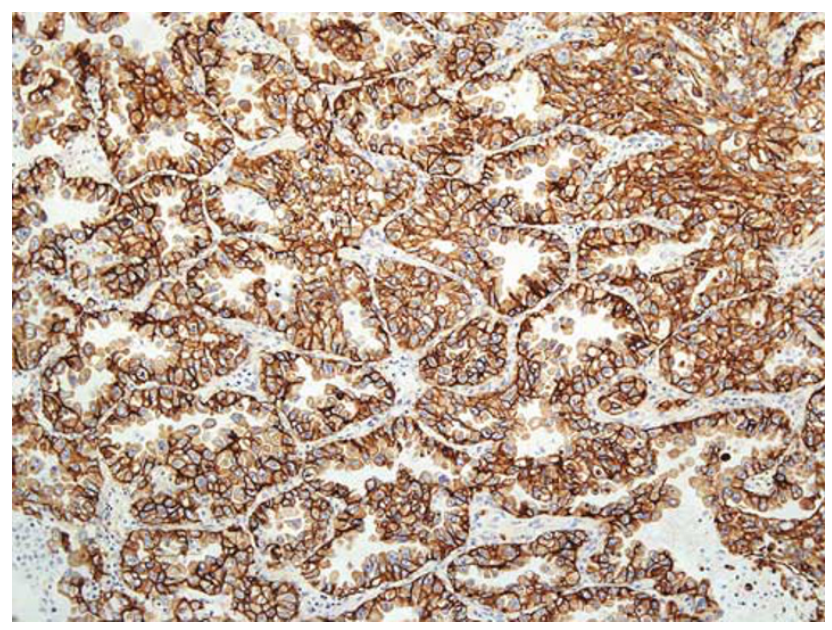

Figure 1 EGFR protein expression by immunohistochemistry: score 400 (intensity 4 in $100 \%$ of cells). 
$\mathrm{ddH}_{2} \mathrm{O}$. Single-base primer extention (SNPStart, Beckman Coulter no. A23506) using $2 \mathrm{ml}$ of amplified DNA, $2 \mathrm{ml}$ of L858R primer (1 mM), and $4 \mathrm{ml}$ of SNPStart Master mix, and $2 \mathrm{ml}$ of nuclease free $\mathrm{H}_{2} \mathrm{O}$ was performed at $90^{\circ} \mathrm{C}$ for $10 \mathrm{~s}$ and $45^{\circ} \mathrm{C}$ for 25 cycles. The SNPStart reaction was diluted in $40 \mathrm{ml}$ of capillary electrophoresis preparation solution (Beckman Coulter no. A20174) and $0.5 \mu \mathrm{l}$ of capillary electrophoresis size standard 80 (Beckman coulter no. 608395). Separation conditions were $50^{\circ} \mathrm{C}$ with a $30 \mathrm{~s}$ injection at $2.0 \mathrm{kV}$ and separation for $60 \mathrm{~min}$ at $4.8 \mathrm{kV}$. Only sharp, distinct peaks above 500 RFU were evaluated. Because of small amounts of pull up peaks within $5 \mathrm{bp}$ of the expected WT peak of $208 \mathrm{bp}$ (version 1) or $250 \mathrm{bp}$ (version 2 including exon 20) were repeated before being considered positive (Figure 2).

\section{FISH Analysis}

The 100 tumor sections were microdissected and incubated at $60^{\circ} \mathrm{C}$ overnight, deparaffinized in xylene washes and dehydrated using $100 \%$ ethanol followed by a $20 \mathrm{~min}$ incubation in $0.2 \mathrm{~N}$ hydrochloric acid after briefly being dried at $50^{\circ} \mathrm{C}$. The sections were then placed in $\mathrm{dd}_{2} \mathrm{O}$ for $3 \mathrm{~min}$. The sections were then incubated in sodium thiocynate buffer for $30 \mathrm{~min}$ at $80^{\circ} \mathrm{C}$, washed in $\mathrm{ddH}_{2} \mathrm{O}$ followed by two washes in $2 \times$ saline sodium citrate buffer. A digestion with pepsin buffer at $20-25^{\circ} \mathrm{C}$ for $25 \mathrm{~min}$ was then performed followed by two washes in $2 \times$ sodium citrate buffer. After brief drying, the slides were then fixed in $10 \%$ formalin for $10 \mathrm{~min}$ at $20-25^{\circ} \mathrm{C}$, followed by two washes in $2 \times$ sodium citrate buffer and a brief drying. The slides were then dehydrated through an ethanol series of 70, 85 and $100 \%$. Dual target, dual color FISH assays were performed using the LSI EGFR SpectrumOrange/ CEP 7 SpectrumGreen probe (Vysis; Downers Grove, IL, USA). The hybridization area was sealed with glass cover slip and rubber cement following the application of the probe. Codenaturation of the chromosomal and probe DNA was achieved at $73^{\circ} \mathrm{C}$ for $5 \mathrm{~min}$, hybridization was achieved in a humidified chamber at $37^{\circ} \mathrm{C}$ up to $8 \mathrm{~h}$. Post-hybridization
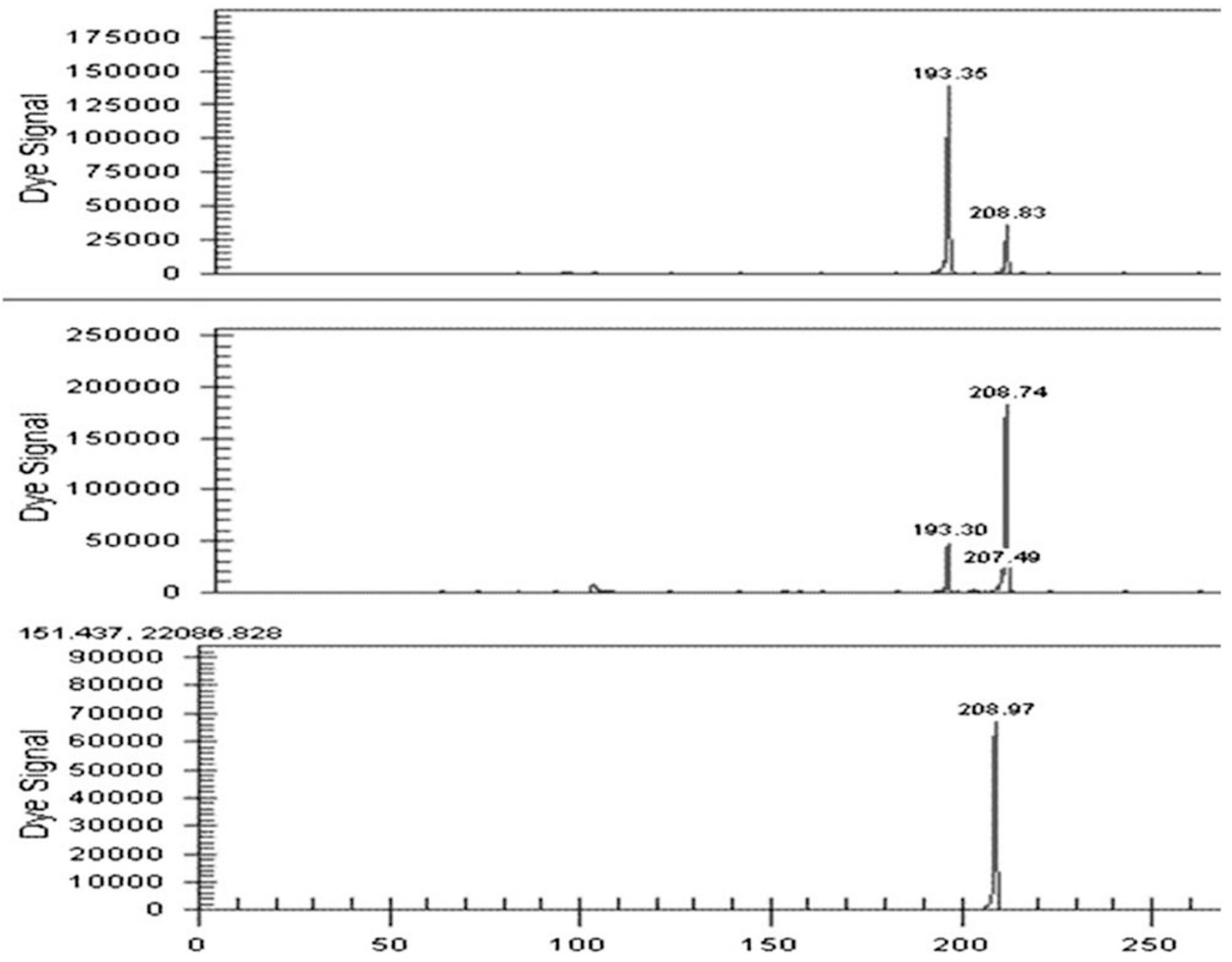

Figure 2 Detection of EGFR mutations by PCR. EGFR homozygous deletion mutation (top panel) and low-level (middle panel) mutation in exon 19 by PCR and negative control (bottom panel). 


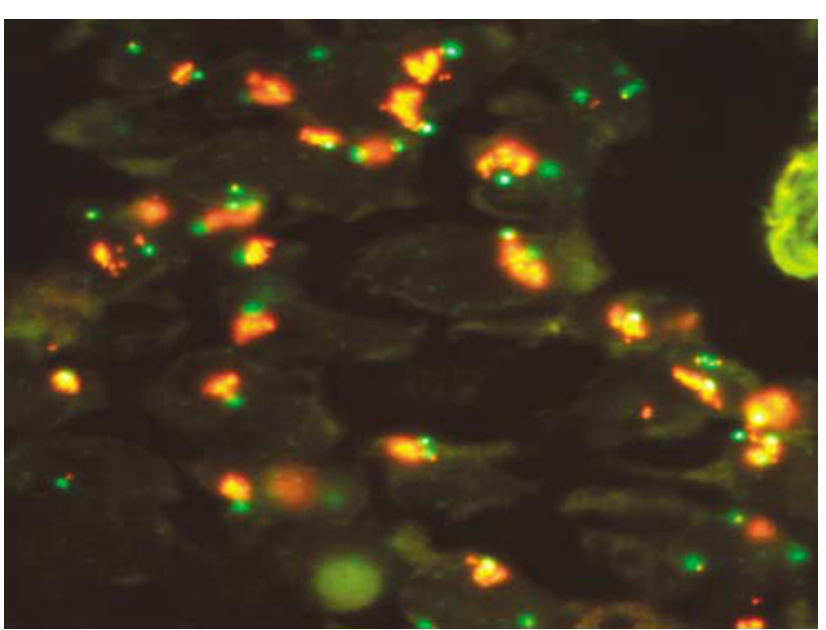

Figure 3 Detection of increased copy numbers of EGFR gene by FISH. EGFR (red) and CEP 7 (green) showing clustered gene amplification.

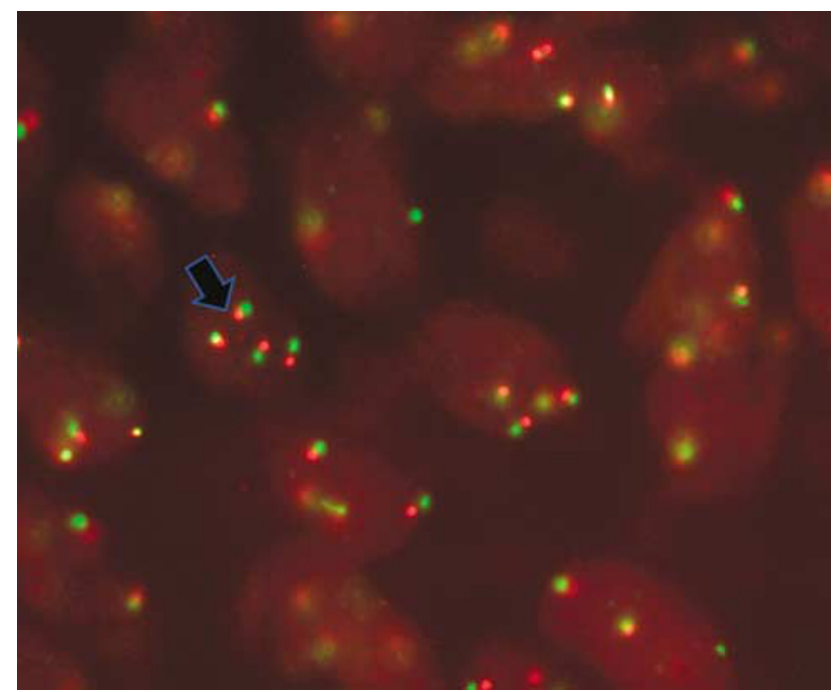

Figure 4 Detection of increased copy numbers of EGFR gene by FISH. EGFR (red) and CEP 7 (green) showing high polysomy (arrow), four or more copies were seen in more than $40 \%$ of the nuclei in this case.

washes were performed in $2 \times$ sodium citrate $/ 0.3 \%$ $\mathrm{NP} 40 ; \mathrm{pH} 7.0$ at $80^{\circ} \mathrm{C}$ for $2 \mathrm{~min}$ and $1 \mathrm{~min}$ at room temperature. The slides were then stained with a 1:1 mixture of $4^{\prime} 6$-diamidino-2-phenylindole (DAPI) (Vector Laboratories, Burlingame, CA, USA) and mounting medium for fluorescence (Vector Laboratories) for chromatin counterstaing. Analysis was performed on a fluorescence microscope. The EGFR sequence was visualized using a Texas red filter, the chromosome 7 centromere sequence was visualized with a fluorescein isothiocynate filter and the nuclei were identified with a DAPI filter. Gene amplification and polysomy were defined as per the criteria suggested by Hirsch et al; FISH negative with no or low genomic gain ( $\leq$ four copies of gene in $>40 \%$ of the cells) and FISH positive with gene amplifica- tion, defined by the presence of tight gene clusters, a gene/chromosome per cell ratio $\geq 2$, or $\geq 15$ copies of the genes per cell in $\geq 10 \%$ of the analyzed cells (Figure 3) or with high polysomy ( $\geq$ four copies of the gene in $\geq 40 \%$ of the cells) (Figure 4 ). ${ }^{17}$

Appropriate positive and negative controls were performed for all three tests.

\section{Statistical analysis}

Kappa correlation, analysis of variance (ANOVA), and sensitivity, and negative predictive values of each test were calculated using SPSS (Chicago, IL, USA) version 11.5. Analysis with ANOVA was performed using the following comparisons of the various test results: IHC with FISH, IHC with PCR and FISH with PCR. A positive result by any test was arbitrarily used as 'true positive' in the calculations of sensitivity and negative predictive values.

\section{Results}

Positive immunoreactivity for EGFR as defined by Hirsch et al criteria was noted in $62 \%$ of the cases (Table 1). Among these, 17 demonstrated an IHC score of 350-400, 36 demonstrated an IHC score of 300-349 and 9 demonstrated a score of 250-299 but were considered as positive after examination by two pathologists. In-frame deletions in exon 19 were detected in $10 \%$ cases and L858R missense mutation in exon 21 were detected in $14 \%$ cases. Polysomy and amplification were noted in 29 and $11 \%$ of the cases, respectively, by FISH. Sixteen cases were found to be positive by all three tests, IHC, PCR and FISH. Among the 62 cases that were immunoreactive by IHC, 32 also showed polysomy or amplification by FISH whereas 22 cases demonstrated mutation or deletion by PCR. Among the 40 cases that demonstrated polysomy or amplification by FISH, 17 cases also showed mutation or deletion by PCR (Table 1). The results of IHC, PCR and FISH did not significantly correlate with each other when Hirsch criteria were applied for IHC interpretation: the $\kappa$ statistics showed low concordance with values between 0.2 and 0.3 and ANOVA was significant at $P<0.05$ (Table 2). However, among the 17 cases with IHC scores of 350-400, 14 cases also demonstrated amplification or polysomy as detected by FISH, resulting in a significant correlation between these two findings $(P=0.01)$. There was no correlation between IHC scores and PCR results. Using the semi-arbitrary criterion of identifying a positive result by any of the three methods as a 'true positive result', the sensitivities for detection of EGFR abnormalities were $87 \%$ for IHC, $56 \%$ for FISH and $33 \%$ for PCR. A combination of IHC and FISH had the highest sensitivity at $98 \%$. The negative predictive values of IHC, FISH and PCR were 0.76, 0.48 and 0.38 , respectively. A combination of IHC 
Table 1 Percentage of pulmonary adenocarcinomas that showed EGFR molecular or phenotypic abnormalities $(n=100)$

\begin{tabular}{lccccccc}
\hline Test & IHC & PCR & FISH & IHC+PCR+FISH & IHC+PCR & IHC+FISH & FISH+PCR \\
\hline$\%$ positive & $62 \%$ & $24 \%$ & $40 \%$ & $16 \%$ & $22 \%$ & $32 \%$ & $17 \%$ \\
\hline
\end{tabular}

EGFR, epidermal growth factor receptor; FISH, fluorescent in situ hybridization; IHC, immunohistochemistry; PCR, polymerase chain reaction. Molecular analysis: in-frame deletions in exon 19 and L858R missense mutation in exon 21 were evaluated.

Table 2 Comparison of EGFR positive test results obtained with IHC, molecular analysis and FISH* $(n=100)$

\begin{tabular}{lccc}
\hline Statistical tests & IHC and FISH & PCR and FISH & IHC and PCR \\
\hline Kappa correlation & 0.3 & 0.3 & 0.2 \\
ANOVA & 0.002 & 0.00 & 0.001 \\
\hline
\end{tabular}

ANOVA, analysis of variance; EGFR, epidermal growth factor receptor; FISH, fluorescent in situ hybridization; IHC, immunohistochemistry; PCR, polymerase chain reaction.

Molecular analysis: in-frame deletions in exon 19 and L858R missense mutation in exon 21 were evaluated.

and FISH had the best negative predictive value of $0.97 \%$.

\section{Discussion}

Our results demonstrate that EGFR overexpression, amplification, polysomy and selected mutations are independent variables, suggesting the need to test pulmonary adenocarcinomas with more than one methodology to detect different EGFR molecular and phenotypic abnormalities. The sensitivities of the three methods for detection of EGFR abnormalities were 87,56 and $33 \%$ for IHC, FISH and PCR, respectively. Testing with both IHC and FISH provided a negative predictive value of 0.97 for detection of EGFR deletions in exon 19 and insertions in exon 21, suggesting that it may not be costeffective to test for these mutations in the neoplasms that exhibit a negative test result with the other two methods. Also IHC scores of 350-400 were found to correlate with presence of amplification or polysomy as detected by FISH, thus indicating that stringent criteria for interpretation of IHC need to be established. Clinical follow-up information about the 100 cases studied with IHC, FISH and PCR is not currently available, but our recent systematic literature review with meta-analysis of over 5000 patients concluded that EGFR overexpression, amplification, polysomy and the two mutations tested for in this study significantly correlated with the clinical response of patients with pulmonary adenocarcinoma to tyrosine kinase inhibitors therapy. ${ }^{7}$

There is considerable conflicting information regarding the correlation between the results of different EGFR tests. For example Hirsch et al found correlation between high copy number as detected by FISH and EGFR overexpression as detected by
IHC. ${ }^{12}$ All the neoplasms in this study that demonstrated gene amplification by FISH also showed EGFR protein overexpression by IHC, suggesting that high gene copy number either in the form of amplification or polysomy had an impact on the level of protein expression; the impact was found to be statistically significant if strong intense membranous immunoreactivity was noted in more than $90 \%$ of the cells. In contrast, Bell et al did not detect a correlation between the results obtained by IHC and FISH. ${ }^{13}$ These findings may suggest that stringent criteria for interpretation of IHC are needed and only strong complete membranous immunoreactivity in greater than $90 \%$ of the cells may be considered as true positive.

Inconsistent results have also been reported regarding correlation between detection of EGFR mutations and EGFR gene amplification/polysomy as detected by FISH. For example, Sone et al, in a study of 59 patients showed a correlation between EGFR mutations detected by PCR and amplification detected by FISH. ${ }^{18}$ In contrast, the studies by Bell et al and Endo et al did not find a correlation between the results of FISH and molecular analysis and proposed that EGFR kinase mutations and gene amplifications appear to identify different genetic subsets of pulmonary adenocarcinoma. ${ }^{13,14}$ The study by Bell et al is of particular interest as it used quantitative PCR, a precise method to evaluate for EGFR gene copy number and distinguish specific amplification from non-specific aneuploidy. ${ }^{13}$ However, this study did not evaluate the results with statistical methods. A recent study by Li et al using PCR to detect deletions within exon 19 and the L858R mutation in exon 21, expression by IHC and EGFR amplification using chromogenic in situ hybridization (CISH) showed that EGFR amplification is often associated with EGFR mutation. ${ }^{15}$ Their results showed a statistically significant association between IHC and CISH but lack of correlation between IHC and EGFR mutations. ${ }^{15}$

In summary, our experience with testing 100 patients with advanced pulmonary adenocarcinoma with IHC, FISH and PCR show that the test results are independent variables, except for a significant correlation between high IHC scores (350-400) and FISH, suggesting that these neoplasms should be evaluated with more than one method to identify the largest proportion of patients that may benefit from tyrosine kinase inhibitors therapy. Two major recent clinical trials, BR21 and IDEAL, have concluded 
that EGFR protein overexpression was not predictive of response to erlotinib or gefitinib therapy and that these drugs provided maximum benefit in patients with tyrosine kinase mutations. ${ }^{13,19}$ However, our recent meta-analysis of data from 5000 pulmonary adenocarcinoma patients reported in 27 studies, including both the B21 and IDEAL trial results, showed that IHC, FISH and PCR were all associated with significant response to tyrosine kinase inhibitors therapy., ${ }^{7,119}$ The somewhat variable and conflicting information available in the literature suggests that there is a need to develop evidence-based or consensus standardization guidelines for the performance and interpretation of EGFR tests in routine clinical practice.

\section{References}

1 Jemal A, Thomas A, Murray T, et al. Cancer statistics, 2002. CA Cancer J Clin 2002;52:23-47.

2 Hirsch FR, Witta S. Biomarkers for prediction of sensitivity to EGFR inhibitors in non-small cell lung cancer. Curr Opin Oncol 2005;17:118-122.

3 Sasaki H, Endo K, Okuda K, et al. Epidermal growth factor receptor gene amplification and gefitinib sensitivity in patients with recurrent lung cancer. J Cancer Res Clin Oncol 2008;134:569-577.

4 Clark G, Cameron T, Das Gupta A, et al. Clinical benefits of erlotinib in male smokers with squamous cell NSCLC. J Clin Oncol 2006;24(Suppl 18S):7166.

5 Chou TY, Chiu CH, Li LH, et al. Mutation in the tyrosine kinase domain of epidermal growth factor receptor is a predictive and prognostic factor for gefitinib treatment in patients with non-small cell lung cancer. Clin Cancer Res 2005;11:3750-3757.

6 Kakiuchi S, Daigo Y, Ishikawa N, et al. Prediction of sensitivity of advanced non-small cell lung cancers to gefitinib (Iressa, ZD1839). Hum Mol Genet 2004;13:3029-3043.

7 Gupta R, Dastane A, Mckenna RJ, et al. The predictive value of EGFR tests in patients with pulmonary adenocarcinoma: review of current 'Best Evidence' with Meta-Analysis. Hum Pathol 2008 (in press).

8 Cappuzzo F, Hirsch FR, Rossi E, et al. Epidermal growth factor receptor gene and protein and gefitinib sensitivity in non-small-cell lung cancer. J Natl Cancer Inst 2005;97:643-655.

9 Hirsch FR, Varella-Garcia M, Cappuzzo F, et al. Combination of EGFR gene copy number and protein expression predicts outcome for advanced nonsmall-cell lung cancer patients treated with gefitinib. Ann Oncol 2007;18:752-760.

10 Parra HS, Cavina R, Latteri F, et al. Analysis of epidermal growth factor receptor expression as a predictive factor for response to gefitinib ('Iressa', ZD1839) in non-small-cell lung cancer. Br J Cancer 2004;91:208-212.

11 Mitsudomi T, Kosaka T, Endoh H, et al. Mutations of the epidermal growth factor receptor gene predict prolonged survival after gefitinib treatment in patients with non-small-cell lung cancer with postoperative recurrence. J Clin Oncol 2005;23: 2513-2520.

12 Hirsch FR, Varella-Garcia M, Bunn Jr PA, et al. Epidermal growth factor receptor in non-small-cell lung carcinomas: correlation between gene copy number and protein expression and impact on prognosis. J Clin Oncol 2003;21:3798-3807.

13 Bell DW, Lynch TJ, Haserlat SM, et al. Epidermal growth factor receptor mutations and gene amplification in non-small-cell lung cancer: molecular analysis of the IDEAL/INTACT gefitinib trials. J Clin Oncol 2005;23:8081-8092.

14 Endo K, Sasaki H, Yano M, et al. Evaluation of the epidermal growth factor receptor gene mutation and copy number in non-small cell lung cancer with gefitinib therapy. Oncol Rep 2006;16:533-541.

$15 \mathrm{Li}$ AR, Chitale D, Riely GJ, et al. EGFR mutations in lung adenocarcinomas: clinical testing experience and relationship to EGFR gene copy number and immunohistochemical expression. J Mol Diagn 2008;10:242-248.

16 Travis W, Colby T, Corrin B, et al. Histologic typing of tumors of lung and pleura. In: Travis WD, Brambilla E, Müller-Hermelink HK, Harris CC (eds). World Health Organization International Classification of $\mathrm{T}$ umors, 3rd edn. Springer-Verlag: New York, 1999, pp $35-44$.

17 Hirsch FR, Varella-Garcia M, McCoy J, et al. Increased epidermal growth factor receptor gene copy number detected by fluorescence in situ hybridization associates with increased sensitivity to gefitinib in patients with bronchioloalveolar carcinoma subtypes: a Southwest Oncology Group Study. J Clin Oncol 2005;23: 6838-6845.

18 Sone T, Kasahara K, Kimura H, et al. Comparative analysis of epidermal growth factor receptor mutations and gene amplification as predictors of gefitinib efficacy in Japanese patients with nonsmall cell lung cancer. Cancer 2007;109:1836-1844.

19 Tsao MS, Sakurada A, Cutz JC, et al. Erlotinib in lung cancer-molecular and clinical predictors of outcome. N Engl J Med 2005;353:133-144. 